\title{
Report on postgraduate training event in science education writing
}

\section{Peter Samuels}

Coventry University, UK

\author{
Mary Deane \\ Oxford Brookes University, UK
}

\section{Jeanne Griffin}

Università di Torino, Italy

\begin{abstract}
This article reports on a case study of a Writing in the Disciplines intervention for doctoral students in science education held at Coventry University in May 2010. Differences between this event and previous ones are described, including the use of an online writing peer review system. Issues that emerged during discussions on the day and the performance of the online writing review system are presented. An evaluation of the event is described. A discussion is provided on the importance of developing social communities in writing, the effectiveness of supporting them with an online writing peer review system and the tensions created by the provision of subject specialist feedback alongside generic writing specialist feedback. Conclusions are drawn for the design of future writing training events.
\end{abstract}

Keywords: Writing in the Disciplines, Mathematics Education, Postgraduate Research, Online Writing Peer Review Systems

\section{Introduction}

The aim of Writing in the Disciplines (WiD) interventions is to support writers' development within the context of their disciplinary studies by cultivating their confidence, know-how, and productivity as authors (Kennedy and Kennedy, 2007). The culture and conventions of publication writing are distinctive in each discipline, so it can be beneficial 
to teach novice writers in a specific discipline how to succeed and offer them opportunities to practice writing journal articles in a safe, supportive environment.

The one-day WiD event reported on here was organised at Coventry University, under the aegis of sigma, formerly the HEFCE-funded Centre for Excellence in University-Wide Mathematics and Statistics Support (www.sigma-cetl.ac.uk), in collaboration with the Centre for Academic Writing at Coventry University (www.coventry.ac.uk/caw; see Samuels and Deane, 2008; 2011). This event was the fourth in a series of workshops on the same theme of discipline-based writing development (see Table 1). It concentrated on capacity building within a cohort of postgraduate research students who were writing for publication for the first time. These students received training on planning, drafting, and revising journal articles, as well as tips on how to undertake peer review to support each other and develop confidence as authors. There were eleven participating students who were supported by six facilitators in order to ensure that they received both a range and depth of feedback and support. The majority of the participants travelled from Limerick in Ireland to Coventry in England due to a partnership between sigma and the Irish National Centre for Excellence in Mathematics and Science Teaching and Learning (http://www.nce-mstl.ie/) which is based there. Whereas at previous events the only discipline covered was mathematics education, at this workshop there were also participants from the field of engineering education through a collaboration with the Engineering Centre for Excellence in Teaching and Learning (engCETL - see http://www.engcetl.ac.uk/). 
Table 1. Summary of the 'sigma' academic writing training events.

\begin{tabular}{|l|l|l|l|}
\hline \multicolumn{1}{|c|}{ Date } & Length & \multicolumn{1}{|c|}{ Content and its motivation } & $\begin{array}{l}\text { No. students } \\
\text { attending }\end{array}$ \\
\hline June 2007 & 1 day & Introduction to writing for publication & 5 \\
\hline December & 1 day & $\begin{array}{l}\text { Emphasis on critical evaluation and } \\
\text { individual feedback (based on student } \\
\text { feedback from the first event) }\end{array}$ & 10 \\
\hline June 2008 & 0.5 day & $\begin{array}{l}\text { Writing and reviewing abstracts } \\
\text { motivated by the students organising } \\
\text { their own conference }\end{array}$ & 5 \\
\hline May 2010 & 1 day & $\begin{array}{l}\text { More applied training on writing for } \\
\text { publication with peer review via SWoRD, } \\
\text { free writing time, and individual feedback }\end{array}$ & $\begin{array}{l}11 \text { (plus 2 } \\
\text { virtually) }\end{array}$ \\
\hline
\end{tabular}

The main aim of this fourth workshop was to promote the students' confidence and independence in writing. This was facilitated through the use of an online peer review tool called 'Scaffolded Writing and Rewriting in the Discipline' (SWoRD) (Cho and Schunn, 2007; see also https://sites.google.com/site/swordlrdc/). This tool enabled the students to submit and view drafts and give their assigned partner feedback based on pre-defined criteria. It was chosen on an experimental basis because it appeared to have the potential of combining peer reviews with specialist reviews, as was planned in the training event.

\section{Structure of the event}

Twelve students originally committed themselves to attending the event and to providing draft papers beforehand. They were organised into pairs and also groups of four. They were given a deadline to provide drafts and a second deadline to write a review of the writing partner's paper. They were also given access to the other two papers in their group of four and encouraged to read these as well.

The morning training session on the day was divided into the following subjects: 
- An introduction to the academic writing process - this exposed the students to a five stage model of the writing process and also involved a group task based around reading a journal article and reporting on its structure.

- Journal selection - the journal webpage, author instructions and a sample article were provided for education, mathematics education and engineering education journals that were both accessible and relevant. The students were encouraged to select a suitable journal for their papers.

- Peer review feedback - this was mainly a practical task in which students were given an opportunity to talk through their peer reviews with their writing partners and then to discuss these reviews in their groups of four. The peer reviews were based on seven categories as shown in Table 2. These were designed to expose the students to typical criteria for a peer review from a journal submission. They were also encouraged to appreciate the multi-faceted nature of critical thinking in order to value receiving two or more opinions on their own work. This activity led students into preparation for the micro level goal setting for the free writing session in the afternoon.

The afternoon session was a combination of free writing time and individual feedback appointments with subject specialists. The purpose of this was to expose the students to an experience similar to a mini writing retreat (Moore, 2003). The session was initiated and summarised by the writing specialist using public goal setting: firstly, at the micro level, in relation to what the students intended to achieve during the afternoon's free writing time; and secondly, at the macro level, through the agreed target dates for the submission of the completed papers to journals. This approach was based on Hayes et al.'s (1985) research findings which indicate that public goal setting can improve performance. 
Table 2. Categories used in peer review.

\begin{tabular}{|l|l|}
\hline Category & \multicolumn{1}{|c|}{ Description } \\
\hline 1 & Summary of main points of the paper \\
\hline 2 & Quality and value of research \\
\hline 3 & Demonstration of scholarship and critical thinking \\
\hline 4 & Clarity of argument \\
\hline 5 & Structure and organisation of paper \\
\hline 6 & Presentation and grammar \\
\hline 7 & Overall assessment \\
\hline
\end{tabular}

\section{Description of the event}

The event was attended by ten of the original twelve students who had enlisted, plus an additional late-comer. The original twelve students all provided their drafts beforehand which were also reviewed by the other students before the event. The eleven who attended were each provided with a 15-20 minute review from a subject specialist.

\section{Emergent issues}

A number of issues emerged during the training, both through the sessions and the subsequent discussions. These are summarised below:

- Possible results of a peer review - these are normally: 'accept with minor corrections'; 'major corrections' (subject to a second review); and 'reject'. The major corrections peer review is the hardest to write but also the most valuable as it is the opportunity of the reviewer to advise the author(s) on how to improve their writing style to bring it up to an acceptable standard for publication.

- Handling a negative peer review - upon receiving a negative peer review it is wise to wait (perhaps a few days) until emotions have subsided and re-read the feedback, trying to think about it objectively. It is best to see this experience as a valuable opportunity to improve writing skills.

- Submitting articles to international journals - in academic writing, authors need to be sensitive towards their readers' needs. Therefore they should bear in mind newcomers to their subject and scholars investigating from other fields who may 
need to grasp unfamiliar concepts and terminology. Moreover, the internationalisation of higher education and the universal accessibility of online journals (Sharifian, 2009) imply that papers written in English are also consulted more often nowadays by non-native English language readers. Authors therefore need to provide clear definitions, appropriate word choice and clear sentence structure in order to facilitate a wider scope of readability.

- Understanding reader psychology - readers do not usually read papers in a linear sequence: if their interest is not aroused early on by giving them a way to understand the main aim or result of the paper and evaluate its significance without a great deal of effort, then the paper is almost useless, however important the research may be and however well it may have been carried out.

- The importance of developing an 'anti-real' writing style - students need to understand the genre of academic articles, where the flow of content often bears little relationship to the 'real' process of doing research (and is thus sometimes described as 'anti-real'), and acquire this style themselves.

- Searching back issues of the selected journal - once a target journal has been selected it is good practice to search it for related articles in the last 10 years' issues as reviewers often look to see how a submitted article relates to previously published work within the journal. This is often made much easier with the use of an online keyword search facility.

\section{Performance of the SWoRD system}

The SWoRD online peer review system performed well as a repository because all the students registered with relative ease, were allocated peer review partners, and successfully uploaded their papers for review. The evaluation criteria in Table 2 were created as comment prompts rather than ratings (see Figure 1). Although SWoRD is structured more for summative ratings rather than formative feedback, the students benefitted from this formative feedback opportunity. Some participants used the comment prompts within SWoRD to create their peer reviews. However, some participants were unable to access their peer reviews before the event. The articles for peer review were also sent to the students by e-mail before the event as a precaution. This did not cause a problem because the event was small and the students were going to meet face-to-face to explain their reviews in person later. Indeed, the face-to-face peer reviews appeared to be the most engaging part of the whole day and extra time was given to this activity. 


\section{Figure 1. The peer review assignment in the SWoRD system.}

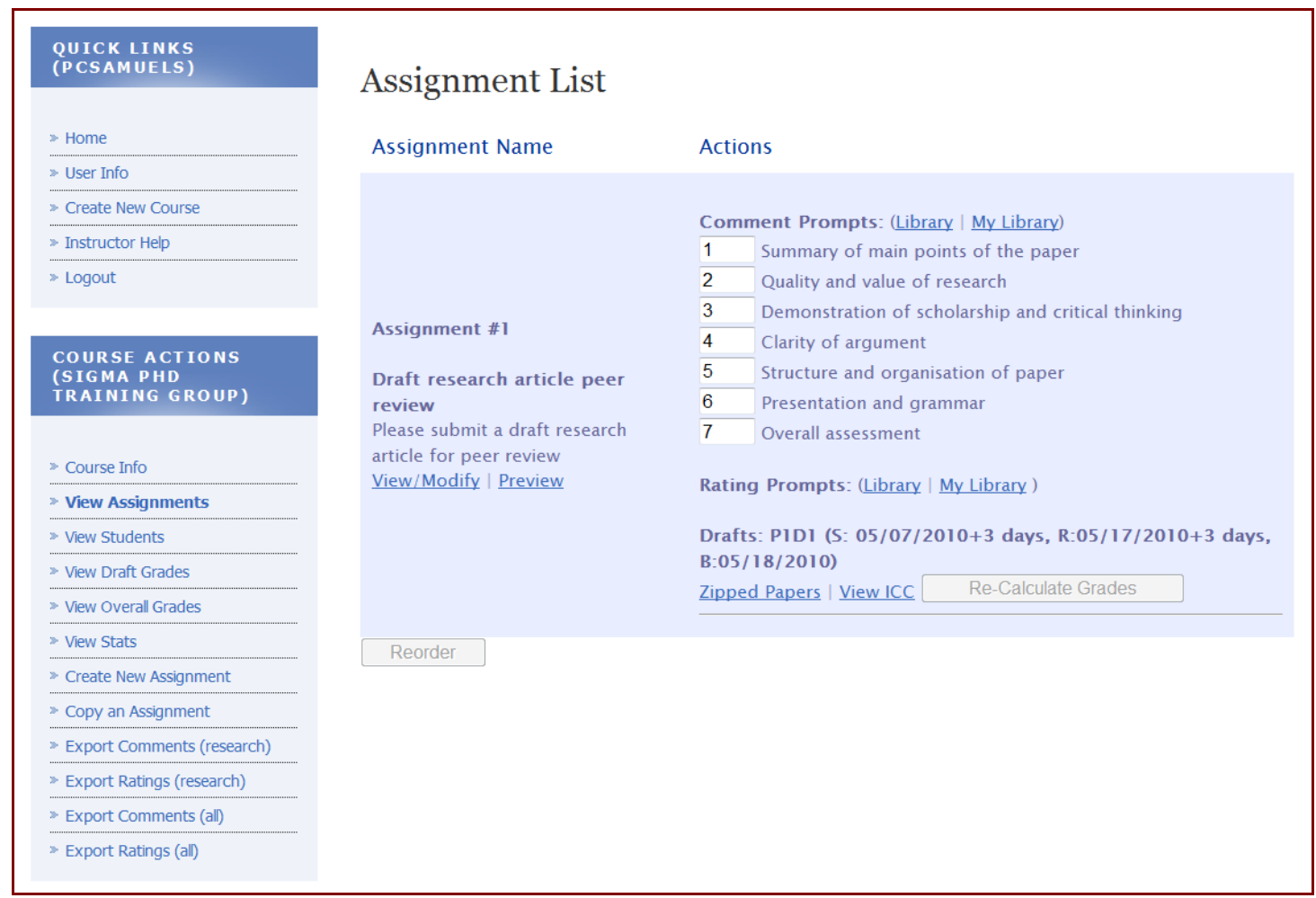

Most of the participants provided goals for the afternoon free writing session and were able to give an account of their progress at the end of the day. Their feedback on these micro level goals then provided strong motivation for the macro goal-setting for the planned submission dates of their revised drafts.

\section{Evaluation}

To evaluate this event, both the students and the facilitators were asked to provide feedback on four questions:

- What have you achieved today?

- What have you learnt from today?

- What did you like about today?

- What would you have changed?

Most of the feedback received was extremely positive. Several students stated that they had gained a greater understanding of the overall process of writing a paper and learnt 
more about the importance of planning their writing. They also appreciated the social environment and the objective feedback they had received on their own work. Several students specifically expressed their appreciation for the opportunity to receive face-toface peer reviews from other students and suggested that more time could be spent on this in a future event.

Some participants indicated that they found it difficult to concentrate in the free writing session in the afternoon. This may have been due to their having to get up very early to fly to the event from Ireland. However, similar feedback had been received at other events appearing to indicate that, despite explicit communication beforehand, some students still did not have the expectation of spending time writing at the event itself, indicating that this still remains an unfamiliar experience for many students.

In addition to the participants' feedback, it was noted that the workload for one of the subject specialists was extremely heavy as they had to provide feedback on eight papers plus take the lead in facilitating the event, according to the principles of WiD interventions. On reflection, it would have been better to have split the roles of specialist writing tutoring and event facilitation between two different people. This experience will hopefully lead to better planning of future events.

\section{Discussion}

This experience supports the view that writing is inherently a social process (Ede, 1989). This kind of training, and the writing community that can form around such an event, can take some of the 'sting' out of the negative emotions students may experience when submitting articles for publication and receiving feedback from journal reviewers.

The SWoRD online peer review system performed adequately in helping to organise the peer reviews and facilitate the virtual community functioning to provide and share feedback before and after the event. SWoRD appears to be more appropriate for combining peer and teacher ratings in summative assessment rather than formative comments, yet this tool was more effective than using email and a traditional website, but possibly less effective than a social networking repository, such as a private group in Facebook. 
However, SWoRD's file structure, permissions protocols, and the inbuilt requirement to formulate evaluation criteria were a useful framework for organising the online peer review.

The feedback given by the subject specialists was generally well received and complemented the peer reviews, as indicated by the evaluation feedback. However, subject expert feedback raised an ethical issue concerning the provision of content specific feedback on poor drafts by subject specialists without either professional training in writing tutoring and its associated need for a holistic sensitivity (McGahey and Szumko, 2006) or a working relationship with the students. This concurs with the point already made on the difficulty of providing peer review on drafts requiring major revisions. This is especially difficult in a face-to-face context and could potentially lead to conflict.

\section{Conclusions}

This one-day writing for publication training event was productive for the participants in terms of enhancing their confidence and competence as academic writers in their chosen disciplines. The feedback obtained suggested that the majority were engaged in the activities and considered their own investment of time and effort to be worthwhile. On reflection, six key lessons were learnt by the facilitators of this WiD event:

1. Writing for publication with a practical emphasis on students' work is an excellent subject for a writing training event.

2. It is important to view such training events in the context of the creation of a community of practice - students should be encouraged to participate as much as possible both before and after the event in order that they can get the most out of the experience and so that the sense of community can grow.

3. Online review systems for student writers have the potential to structure and organise feedback on drafts but maybe SWoRD is not the right system (at least in its current state) for handling an event with formative feedback.

4. Face-to-face peer reviews appear to be particularly effective in this kind of training context.

5. It is probably most effective to combine subject specialist feedback with writing specialist feedback in order to get the best of both worlds in terms of content and generic feedback and also avoid possible conflict. 
6. Many postgraduate students are unfamiliar with the concept of community-based writing, and prefer to write in a private space; therefore, perhaps a variety of different possible activities should be given during the free time when individual feedback is being provided.

\section{References}

Cho, K. and Schunn, C.D. (2007) 'Scaffolded writing and rewriting in the discipline: a webbased reciprocal peer review system', Computers and Education, 48(3), pp. 409426 [Online]. Available at: http://www.sciencedirect.com/science/article/B6VCJ4G0493G-1/2/8399c1d42c1f0bae4a850d02e97a6b6a (Accessed: 28 April 2011).

Ede, L. (1989) 'Writing as a social process: a theoretical foundation for writing centers?', The Writing Center Journal, 9(2), pp. 3-13.

Hayes, S.C., Rosenfarb, I., Wulfert, E., Munt, E.D., Korn, Z. and Zettle, R.D. (1985) 'Selfreinforcement effects: an artifact of social standard setting', Journal of Applied Behavior Analysis, 18(3), pp. 201-214.

Kennedy, M. and Kennedy, W. (2007) Writing in the disciplines: a reader and rhetoric for academic writers. $6^{\text {th }}$ edn. Needham Heights, MA: Allyn and Bacon.

McGahey, P. and Szumko, J. (2006) 'Relationship at the heart of helping', BRAINHE 2006 Conference. De Montfort University, Leicester 15 September. Available at: http://www.brainhe.com/staff/types/documents/RelationshipattheHeartofSupportWor k.doc (Accessed: 28 April 2011).

Moore, S. (2003) 'Writers' retreats for academics: exploring and increasing the motivation to write', Journal of Further and Higher Education, 27(3), pp. 333-342.

Samuels, P.C. and Deane, M. (2008) 'Academic writing training for mathematics education PhD students', MSOR Connections, 8(3), pp. 41-44 [Online]. Available at: http://mathstore.gla.ac.uk/headocs/8341 samuels p academicwriting.pdf (Accessed: 28 April 2011). 
Samuels, P.C. and Deane, M. (2011) 'Writing for mathematics education at doctoral level', in Deane, M. and O'Neill, P. (eds.) Writing in the Disciplines. Basingstoke: Palgrave Macmillan, pp. 140-154

Sharifian, F. (ed.) (2009) English as an international language: perspectives and pedagogical issues. New Perspectives on Language and Education. Bristol: Multilingual Matters.

\section{Author details}

Dr Peter Samuels is Visiting Research Fellow at the Serious Games Institute at Coventry University, UK, and an Academic Skills Tutor at Birmingham City University, UK. His research interests include university-level mathematics education (especially the use of new technologies and serious games) and learning development.

Dr Mary Deane is a Consultant with the Oxford Centre for Staff and Learning Development and Oxford Brookes University, UK. Her specialisms include teaching writing in disciplinary contexts, promoting research and publication, enhancing curricula, and internationalisation in higher education.

Jeanne Griffin is an English for Speakers of Other Languages teacher in the Faculty of Mathematical, Physical and Natural Sciences at the University of Torino, Italy. 